\title{
Serum ferritin, serum LDH and d-dimer in correlation with the outcome in Covid-19.
}

\author{
Kishan J. ${ }^{1}$, Byalya K. ${ }^{2 *}$, Kumar V. ${ }^{3}$ \\ DOI: https://doi.org/10.17511/ijmrr.2021.i01.07 \\ 1 J. Hari Kishan, Associate Professor, Department of General Medicine, Kamineni Academy of Medical Sciences and Research Center, \\ Hyderabad, Telangana, India. \\ 2* Karthikeya Byalya, Post-Graduate, Kamineni Academy of Medical Sciences and Research Center, Hyderabad, Telangana, India. \\ ${ }^{3}$ V. Sharvan Kumar, Post-Graduate, Kamineni Academy of Medical Sciences and Research Center, Hyderabad, Telangana, India.
}

BACKGROUND: Early detection of comorbidities, severe patients with SARS-COV-2 and helpful diagnostic tools is very important for individual treatment and helps us in assessing the outcome of moderate to severe patients. METHOD: In our study we have included 108 patients with RT-PCR positive for SARS COV-2 and the samples for D-dimer, Sr. LDH and Sr.ferritin were sent and analyzed. RESULTS: the effect of D-dimer, serum LDH and serum ferritin individually and combinedly showed in our study there was no significant difference between D-dimer and the outcome however there was a significant $p$-value of $<0.001$ with serum LDH and the outcome, and $\mathrm{p}$-value of 0.016 with serum ferritin and outcome. CONCLUSIONS: When the markers individually analyzed they showed a significant association between outcome and markers, in elevated O2and normal patients. Mean D dimer, serum ferritin and serum LDH were high among subjects who required NIV and low among subjects who required $\mathrm{O}$, on Room air and intubated respectively. In hospitalized patients with respiratory distress, we recommend clinicians closely monitor serum ferritin, serum LDH and D-dimer and also other markers of severity, WBC count, lymphocyte count, platelet count, IL-6 as markers for potential progression to critical illness, has been under the study, however our study sample being 108, a study with a larger number of samples required to predict the outcome.

Keywords: COVID 19, Serum ferritin, Serum LDH D-dimer

\section{Corresponding Author}

Karthikeya Byalya, Post-Graduate, Kamineni Academy of Medical Sciences and Research Center, Hyderabad, Telangana, India. Email: karthickbyalya@gmail.com

\section{How to Cite this Article}

Kishan JH, Byalya K, Kumar VS. Serum ferritin, serum $\mathrm{LDH}$ and $\mathrm{d}$-dimer in correlation with the outcome in Covid-19.. Int J Med Res Rev. 2021;9(1):46-53.

Available From

https://ijmrr.medresearch.in/index.php/ijmrr/article/ view/1251
To Browse

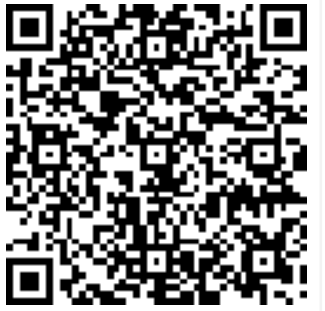

Manuscript Received 2021-02-10

Conflict of Interest No
Review Round 1 2021-02-20

Funding

Nil

Review Round 2
2021-02-25
Ethical Approval
Yes

Review Round 2

Yes
Review Round 3

Plagiarism X-checker $8 \%$
Accepted 2021-02-28

Note 


\section{Introduction}

Several human-tropic coronaviruses (CoVs) constantly circulate in the human population and usually cause mild respiratory disease. Two of these RNA viruses-SARS-CoV-1 and MERS-CoV-had been discovered in 2002 and 2012, respectively, as the cause of severe acute respiratory syndromes.

In December 2019, a new infectious respiratory disease emerged in Wuhan, Hubei province, China. The disease, termed coronavirus disease 19 (COVID-19), rapidly spread from China as a global devastating pandemic

SARS-CoV-2 and SARS-COV-1 are almost 79\% identically similar in sequence. SARS-COV-1, SARSCOV-2 and Middle East respiratory syndrome viruses in the Coronaviridae family, with its positive-sense single-stranded RNA genome containing a surface glycoprotein, and viral envelope is coated by spike (S) glycoprotein, envelope (E), and membrane (M) protein.

S glycoprotein has 2 sub-units S1 and S2, Nterminal S1 subunit contains the receptor-binding domain that binds to the peptidase domain of angiotensin 1 converting enzyme 2 (ACE 2) and membrane-proximal S2 subunit helps in membrane fusion highly preserved and is considered a potential antiviral target.

It has been almost a year since the first case of SARS-COV-2 has been reported, and the pathogenesis is still based on cytokine storm, and as the SARS-COV-2 has the greater affinity to bind to ACE-2 receptors. On the airway epithelial cells and vascular endothelial cells a transmembrane cell surface protein (serine protease 2 ) the virus bind to ACE 2 receptor which is in synergy with the host's transmembrane serine protease 2 receptor.

Predicting the prognosis and outcome is a bit challenging for physicians. COVID-19 causes high mortality with widespread inflammation and cytokine storm, excessive activation of the immune system and monocyte-macrophage system activation, damage occurs in many organs, especially the lungs.

At present day, there are 104 million cases and Indian stats say around 11 million cases have been reported till the day, with an average of 8,000 news cases per day with a significant reduction in the death rate of an average 100 per day in India.
Over 90 vaccine and 50 antibody approaches are currently being explored [1]. Most target the homotrimeric Spike protein, which mediates host cell binding and entry and is the major target of neutralizing antibodies [2],[3].

On the verge of vaccine production still the outcome and prognosis yet to be assessed, in our study, we have shown that the increase in the biochemical parameters such as ferritin, serum LDH, d-dimer, measured at the first time of hospital admission of patients with RT-PCR positive for SARS-COV-2 helps us in assessing the outcome or if the patient might require mechanical ventilator support or can be managed on oxygen support.

As the real-time RT-PCR is now available and has found that initial qRT-PCR pharyngeal swab sensitivity ranged from $66 \%-80 \%$ [4], but qRT-PCR sensitivity of $71 \%$ compared to chest computed tomography (CT) sensitivity of $98 \%$ was found in Fang et al [5]. Patient with typical clinical features and identical specific CT images have elicited false negatives by qRT-PCR [ㅁ].

\section{Methods and materials}

This is a retrospective observational study of 108 patients diagnosed with COVID 19 pneumonia, patient serum $\mathrm{LDH}$, serum ferritin and D-dimer values were analyzed and oxygen requirement, NIV support during the hospital stay were analyzed using SPSS software version 22, the chi-square test was used as a test of significance for qualitative data, continuous data represented in mean and standard deviation and ANOVA (analysis of variance) was the test of significance to identify the mean difference between more than two groups for quantitative data.

Statistical analysis:

Data were entered into a Microsoft Excel datasheet and was analyzed using SPSS 22 version software. Categorical data was represented in the form of Frequencies and proportions. Chi-square test was used as a test of significance for qualitative data. Continuous data were represented as mean and standard deviation. ANOVA (Analysis of Variance) was the test of significance to identify the mean difference between more than two groups for quantitative data Continuous data were represented as mean and standard deviation. ANOVA (Analysis of Variance) was the test of significance to identify the mean difference between more than two groups for quantitative data. 
Graphical representation of data: MS Excel and MS word was used to obtain various types of graphs such as bar diagram.

P-value (Probability that the result is true) of $<0.05$ was considered as statistically significant after assuming all the rules of statistical tests.

Statistical software: MS Excel, SPSS version 22 (IBM SPSS Statistics, Somers NY, USA) was used to analyze data.

\section{Results}

Table 1: D Dimer levels concerning the outcome.

\begin{tabular}{|l|l|l|l|l|l|l|l|}
\hline \multicolumn{2}{|c|}{} & \multicolumn{5}{|c|}{ D DIMER } & \multirow{2}{*}{ P-value } \\
\cline { 2 - 7 } & Mean & SD & Median & Minimum & Maximum & \\
\hline \multirow{3}{*}{ Outcome } & Room air & 4037.9 & 17296.7 & 499.5 & 170.0 & 98600.0 & \multirow{2}{*}{0.230} \\
\cline { 2 - 7 } & O2 & 1635.5 & 2799.3 & 759.5 & 196.0 & 14300.0 & \\
\cline { 2 - 6 } & NIV & 8468.0 & 19437.7 & 1650.0 & 200.0 & 95200.0 & \\
\cline { 2 - 6 } & Intubated & 7795.6 & 12244.1 & 2940.0 & 800.0 & 29500.0 & \\
\hline
\end{tabular}

In the study there was no significant difference in mean D Dimer levels concerning the outcome. Mean D dimer was high among subjects who required NIV and low among subjects who required $\mathrm{O} 2$.

Table 2: Serum LDH levels concerning the outcome.

\begin{tabular}{|l|l|l|l|l|l|l|l|}
\hline \multicolumn{2}{|c|}{ Table 2 } & \multicolumn{5}{|c|}{ Serum LDH } & \multirow{2}{*}{ P-value } \\
\cline { 2 - 7 } & Mean & SD & Median & Minimum & Maximum & \\
\hline \multirow{3}{*}{ Outcome } & Room air & 289.2 & 75.6 & 290.0 & 166.0 & 435.0 & \multirow{2}{*}{$<0.001^{*}$} \\
\cline { 2 - 7 } & O2 & 459.2 & 150.7 & 443.0 & 186.0 & 840.0 & \\
\cline { 2 - 7 } & NIV & 610.7 & 268.9 & 532.0 & 308.0 & 1568.0 & \\
\cline { 2 - 7 } & Intubated & 549.4 & 267.3 & 592.0 & 139.0 & 849.0 & \\
\hline
\end{tabular}

In the study there was a significant difference in mean serum LDH levels concerning Outcome. Mean Serum LDH was high among subjects who required NIV and low among subjects who required Room air.

Table 3: Serum Ferritin levels concerning the Outcome.

\begin{tabular}{|c|c|c|c|c|c|c|c|}
\hline \multirow{2}{*}{\multicolumn{2}{|c|}{ Table 3}} & \multicolumn{5}{|c|}{ Serum Ferritin } & \multirow{2}{*}{$\begin{array}{c}P- \\
\text { value }\end{array}$} \\
\hline & & Mean & $\begin{array}{l}\text { Standard } \\
\text { Deviation }\end{array}$ & Median & Minimum & Maximum & \\
\hline \multirow[t]{4}{*}{ Outcome } & Room air & $\begin{array}{l}270 . \\
5\end{array}$ & 259.6 & 182.1 & 9.3 & 848.0 & $\begin{array}{l}0.016 \\
*\end{array}$ \\
\hline & 02 & 533. & 425.5 & 446.4 & 15.2 & 1654.3 & \\
\hline & NIV & $\begin{array}{l}899 . \\
1\end{array}$ & 1355.8 & 514.7 & 101.7 & 6927.6 & \\
\hline & Intubated & $\begin{array}{l}344 . \\
2\end{array}$ & 97.9 & 340.1 & 256.4 & 440.0 & \\
\hline
\end{tabular}

In the study there was a significant difference in mean Serum Ferritin levels concerning Outcome. Mean Serum Ferritin was high among subjects who required NIV and low among subjects who were Intubated.

Table 4: Association between Outcome and D Dimer.

\begin{tabular}{|c|c|c|c|c|c|}
\hline \multicolumn{2}{|c|}{ Table 4} & \multicolumn{4}{|c|}{$\overline{D \text { DIMER }}$} \\
\hline & & \multicolumn{2}{|c|}{$<440 \mathrm{ng} / \mathrm{ml}$} & \multicolumn{2}{|c|}{$>440 \mathrm{ng} / \mathrm{ml}$} \\
\hline & & Count & $\%$ & Count & $\%$ \\
\hline \multirow[t]{4}{*}{ Outcome } & Room air & 14 & $63.6 \%$ & 18 & $21.2 \%$ \\
\hline & 02 & 5 & $22.7 \%$ & 41 & $48.2 \%$ \\
\hline & NIV & 3 & $13.6 \%$ & 21 & $24.7 \%$ \\
\hline & Intubated & 0 & $0.0 \%$ & 5 & $5.9 \%$ \\
\hline
\end{tabular}

$X 2=15.42, \mathrm{df}=3, \mathrm{p}=0.001^{*}$

In the study there was a significant association between Outcome and D Dimer levels. I.e. with an increase in $D$ dimer levels there was the need for O2, NIV and Intubation compared to those with normal D Dimer levels.

Table 5: Association between Outcome and Serum LDH.

\begin{tabular}{|l|l|l|l|l|l|}
\hline \multicolumn{2}{|c|}{ Table 5 } & \multicolumn{4}{|c|}{ LDH } \\
\cline { 3 - 7 } \multicolumn{2}{|c|}{} & 140 to 280 U/L & \multicolumn{2}{l|}{280 U/L } \\
\cline { 2 - 7 } \multicolumn{2}{|c|}{} & Count & $\%$ & Count & $\%$ \\
\hline \multirow{4}{*}{ Outcome } & Room air & 14 & $73.7 \%$ & 18 & $20.5 \%$ \\
\cline { 2 - 7 } & O2 & 4 & $21.1 \%$ & 42 & $47.7 \%$ \\
\cline { 2 - 6 } & NIV & 0 & $0.0 \%$ & 24 & $27.3 \%$ \\
\cline { 2 - 6 } & Intubated & 1 & $5.3 \%$ & 4 & $4.5 \%$ \\
\hline
\end{tabular}

$X 2=22.59, \mathrm{df}=3, \mathrm{p}<0.001^{*}$

In the study there was a significant association between Outcome and Serum LDH levels. Among subjects with normal LDH levels, $21.1 \%$ required $\mathrm{O} 2$ and $5.3 \%$ were intubated, were as among subjects with increased LDH levels, $47.7 \%$ required $\mathrm{O} 2$, $27.3 \%$ required NIV and $4.5 \%$ were intubated.

Table 6: Association between Outcome and Serum Ferritin.

\begin{tabular}{|l|l|l|l|l|l|}
\hline \multicolumn{2}{|c|}{ Table 6 } & \multicolumn{4}{|c|}{ Ferritin } \\
\cline { 3 - 7 } \multicolumn{2}{|c|}{} & \multicolumn{3}{|l|}{ Normal } & \multicolumn{2}{l|}{ Raised } \\
\cline { 2 - 6 } \multicolumn{2}{c|}{} & Count & $\%$ & Count & $\%$ \\
\hline \multirow{4}{*}{ Outcome } & Room air & 21 & $52.5 \%$ & 11 & $16.4 \%$ \\
\cline { 2 - 6 } & O2 & 13 & $32.5 \%$ & 33 & $49.3 \%$ \\
\cline { 2 - 6 } & NIV & 5 & $12.5 \%$ & 19 & $28.4 \%$ \\
\cline { 2 - 6 } & Intubated & 1 & $2.5 \%$ & 4 & $6.0 \%$ \\
\hline
\end{tabular}

$X 2=15.99, \mathrm{df}=3, \mathrm{p}=0.001^{*}$ 
In the study there was a significant association between Outcome and Serum Ferritin levels. Among subjects with normal Ferritin levels, 32.5\% required $02,12.5 \%$ were required NIV and $2.5 \%$ were intubated, were as among subjects with increased Ferritin levels, $49.3 \%$ required $02,28.4 \%$ required NIV and $6 \%$ were intubated.

Our study show's that elevated levels of serum ferritin, serum LDH and D-dimer had shown to be requiring higher $\mathrm{O} 2$ support and some of the patient requiring non-invasive ventilatory support. The effect of D-dimer, serum LDH and serum ferritin individually and combinedly showed in our study there was no significant difference between D-dimer and the outcome however there was a significant $p$ value of $<0.001$ with serum LDH and the outcome, and $p$-value of 0.016 with serum ferritin and outcome.

In our study there was a significant association between D-dimer and the outcome which showed, increase in $\mathrm{D}$ dimer levels there was a need for $\mathrm{O} 2$, NIV and Intubation compared to those with normal D Dimer levels. Among subjects with normal LDH levels, $21.1 \%$ required $\mathrm{O} 2$ and $5.3 \%$ were intubated, were as among subjects with increased $\mathrm{LDH}$ levels, $47.7 \%$ required $02,27.3 \%$ required NIV and $4.5 \%$ were intubated.

Among subjects with normal Ferritin levels, 32.5\% required $02,12.5 \%$ were required NIV and $2.5 \%$ were intubated, were as among subjects with increased Ferritin levels, 49.3\% required O2, 28.4\% required NIV and $6 \%$ were intubated.

\section{Discussion}

As SARS-CoV-2 has spread globally it has accumulated some mutations in the viral genome, which contains geographic signatures [7]. even though the virus had attributed some mutations but does not affect the pathogenicity and transmissibility [8]. Spike glycoprotein helps in the binding which is the first step of infection to the host, such binding triggers a cascade of events leading to the fusion between the host cell and viral membranes entry of the virus into the host cell.

There are many different variants out of which the newer one G614 variant has been hypothesized to increase infectivity and transmissibility of the virus. With the G614 variant higher viral load was observed although no association was made with severity in outcomes, These findings have yet to be confirmed with regards to natural infection.
The ACE 2 receptors are distributed in different tissues, the ACE 2 receptor is found on the epithelium of other organs such as the intestine and endothelial cells in the kidney and blood vessels, which may explain gastrointestinal symptoms and cardiovascular complications [9].

Dysregulated synthesis and release of proinflammatory cytokines is thought to be a pathogenetic hallmark of most severe forms of COVID-19 [10,11] but the COVID-19 induced lunginjury is still unclear.

Ferritin is a systemic inflammatory marker that can be used to predict the severity and mortality of SARS-COV-2 disease. Ferritin is also a key mediator of immune dysregulation, under extreme hyperserotonemia, which is via direct immunosuppressive and pro-inflammatory effects, which contributing to the cytokine storm and inflammatory storm. Inflammation regulates iron homeostasis.

The inflammatory response in COVID-19 is involved in the progression from mild cases to severe cases [12]. Hepcidin is a newly discovered marker that regulates iron absorption through regulation of the gastrointestinal tract and iron release, which are both important pathways involved in the regulation of iron availability for incorporation. Hepcidin levels are upregulated in inflammations commonly induced by infections [13].

COVID-19 may be the fifth member of hyperserotonemia syndromes[14] so far comprising four clinical entities, septic shock, macrophage activation syndrome (MAS), Still's a disease in adults (AOSD), and catastrophic antiphospholipid syndrome (CAPS) [15]. All these diseases are characterized by both an extremely elevated serum ferritin level and a partly life-threatening hyperinflammation.

Ferritin expression is strongly regulated by the iron response element/iron regulatory protein (IRE/IRP)dependent mechanisms at the translational level [16]. Apart from regulation by IRE/IRP-dependent mechanisms biosynthesis of ferritin is regulated by cytokines at both transcriptional and translational levels [17].

Whether serum ferritin is released by leaky cells or is actively secreted from cells is a matter of debate. While on the other hand with the evidence suggesting that elevated serum ferritin results from cell damage [18]. 
In our study, the elevated levels of serum ferritin show a higher requirement of 02 support or even requiring mechanical ventilator support.

Elevated Serum LDH levels along with elevated ferritin levels in patients who have widespread inflammation are observed leading to ARDS.

Lactate dehydrogenase ( $(\mathrm{DH})$ is an enzyme that helps in the conversion of lactate to pyruvate in the cells and LDH is elevated when there is increased tissue breakdown and involved in the various pathophysiological process.

Elevated serum LDH is observed in many various clinical conditions, such as hemolysis, cancer, severe infections and sepsis, liver diseases, hematologic malignancies, and many others. Some studies suggesting that the serum LDH levels serves as a non-specific indicator of cellular death.

$\mathrm{LDH}$ is released from cells upon damage to their cytoplasmic membrane and is not only a metabolic but also an immune surveillance prognostic biomarker [19],[20]. LDH increases the production of lactate, which leads to the enhancement of immune-suppressive cells and inhibition of cytolytic cells [21]. These changes could weaken the immune response mounted against the viral infection, resulting in more severe disease in patients with elevated LDH.

$\mathrm{LDH}$ is validated for its potential usefulness as biochemical markers for assessing clinical severity and to monitor treatment response in COVID-19 pneumonia increase in LDH has a high specificity for disease progression inflammatory responses reflected the nonspecific responses to hypoxia, tissue injury, and necrosis, indicating a correlation between infectious cells, immune system and inflammatory response variable studies have shown that an elevated serum LDH is an indicator for poor prognosis.

Cytokines normally mediate and regulate immunity, inflammation, and hematopoiesis; however, further exacerbation of immune reaction and accumulation of cytokines in other organs in some patients may cause extensive tissue damage, or a cytokine release syndrome (cytokine storm), resulting in the capillary leak, thrombus formation, and organ dysfunction.[22,23].

There is strong evidence that dysregulated and excessive cytokine release is responsible for rapid progression and high mortality [24,25].
Mechanisms that activate coagulation in SARS-CoV2 infection are not known at present but appear to be linked to inflammatory responses rather than specific properties of the virus [26].

During the early phase of SARS-CoV-2 infection, coagulation test abnormalities are seen but clinical no signs of bleeding can be seen. It is postulated the initial coagulation changes seen in infected patients progress linearly to SIC and then to DIC as a result of SARS-CoV-2 infection but as of now no clear data is suggesting the hypothesis; many other factors even treatment modalities may be responsible for the development of SIC or DIC eventually (or) later in the course. Initial Coagulation test abnormalities seen in infected patients is likely a result of the profound inflammatory response of the host immune system.

As the virus enters the host through droplet spread, binds to the ACE 2 receptors after proofreading and active replication host immune systems activate from the entry point of time, which results in increased productions of proinflammatory cytokines which have pleiotropic effects and activates coagulation cascade, through several procoagulant pathways.

Polyphosphates, derived from microorganisms, activate platelets, mast cells, and factor XII (FXII) in the contact pathway of coagulation, and exhibit other downstream roles in amplifying the procoagulant response of the intrinsic coagulation pathway [27]. Even complement pathways also play a role in the activation of the coagulation system [28].

Although thrombi process neutrophil extracellular traps and individual neutrophil extracellular trap contains cell-free DNA and histones which activate the contact pathway and enhance other prothrombotic pathways resulting in thrombin generation[29,30]. Inflammatory effects of cytokines cause vascular endothelial cells activation and endothelial injury which result increase in prothrombotic properties.

The inflammatory process with COVID-19 and subsequent activation of coagulation is the probable cause for the elevated D-dimer levels [31,32]. Early in COVID-19 infection coagulation test abnormalities have been seen which does not fulfil the usual definition of clinical coagulopathy which might be due to equivalent increase in thrombin generation and increase fibrinolysis this can be label as COVID19- associated coagulopathy [33]. 
Activation of host defence systems results in subsequent activation of coagulation and thrombin generation as critical communication components among humoral and cellular amplification pathways, a term called thromboinflammation or immunothrombosis.

During infections and sepsis increased fibrinolysis have been reported these changes might be due to reductions in coagulation factors which is considered as a fibrinolytic phase of DIC, which may be a late step with advanced disease, and might explain why high D-dimers are associated with the progression of the disease and worse outcomes.

Some patients appear to have a more pronounced inflammatory response to infection with SARS-CoV2 , such as seen with systemic inflammatory response syndrome or cytokine storm, which may explain more dramatic changes in coagulation tests, including significantly elevated D-dimer, especially as the disease progresses

As discussed earlier inflammatory effects of cytokines leading to vascular endothelial dysfunction with SIC, an endothelioma appears to contribute to the pathophysiology of microcirculatory changes in SARS-CoV-2 infections.

Viral replication in the host target cells causing inflammatory cell infiltration, endothelial cell apoptosis, and microvascular prothrombotic effects.

Microcirculatory changes (or) dysfunction contributes to the clinical sequelae in patients with COVID-19.

From a clinical perspective, in addition to the systemic hypercoagulability and potential threat for thromboembolic complications, the described microvascular endothelial injury with microcirculatory clot formation noted, In severe cases of COVID -19 Infection induced coagulopathy and secondary hyperfibrinolysis had been identified. Higher D-dimer levels at the time of admission are suggestive of a worse prognosis of COVID-19. The presence of the SARS-CoV-2 virus within endothelial cells suggests that direct viral effects, as well as perivascular inflammation, may contribute to endothelial cell injury. Likely, endotheliosis, endothelial injury, endothelial cell dysfunction and impaired microcirculatory function in different vascular beds contribute markedly to lifethreatening complications. Pulmonary thrombosis is mostly responsible for the elevation of D-dimer in severe case although more studies required.

\section{Conclusions}

When the markers individually analyzed they showed a significant association between outcome and markers, in elevated O2and normal patients.

\section{What does the study add to the existing knowledge?}

Mean D dimer, serum ferritin and serum LDH were high among subjects who required NIV and low among subjects who required 02 , on Room air and intubated respectively. In hospitalized patients with respiratory distress, we recommend clinicians closely monitor serum ferritin, serum LDH and Ddimer and also other markers of severity, WBC count, lymphocyte count, platelet count, IL-6 as markers for potential progression to critical illness, has been under the study, however our study sample being 108, a study with a larger number of samples required to predict the outcome.

\section{Author's contribution}

Dr. J. Hari Kishan: Concept, study design

Dr. Karthikeya Byalya: Manuscript preparation

Dr. V. Sharvan Kumar: Manuscript preparation

\section{Reference}

01. Cohen J. COVID-19 shot protects monkeys. Science. 2020;368;456-457.

[Crossref]

02. Yuan M, Wu NC, Zhu X, Lee C-CD, So RTY, Lv H, Mok CKP, Wilson IA. A highly conserved cryptic epitope in the receptor-binding domains of SARS-CoV-2 and SARS-CoV. Science. 2020; eabb7269.

[Crossref]

03. Chen $Y$, Lu S, Jia H, Deng $Y$, Zhou J, Huang B, Yu $Y$, Lan J, Wang $W$, Lou $Y$. A novel neutralizing monoclonal antibody targeting the $\mathrm{N}$-terminal domain of the MERS-CoV spike protein. Emerging Microbes and Infections. 2017;6;e37. [Crossref]

04. Ai T, Yang Z, Hou H, Zhan C, Chen C, Lv W, et al. Correlation of chest CT and RT-PCR testing in coronavirus disease 2019 (COVID-19) in ChinaA report of 1014 cases. Radiology 2020;296;E32-40.

[Crossref] 
05. Fang $Y$, Zhang $H$, Xie $J$, Lin $M$, Ying $L$, Pang $P$, et al. Sensitivity of chest CT for COVID-19Comparison to RT-PCR. Radiology. 2020;296;E115-7.

[Crossref]

06. Wang $Y$, Kang $H$, Liu $X$, Tong Z. Combination of RT-qPCR testing and clinical features for diagnosis of COVID-19 facilitates management of SARS-CoV-2 outbreak. J Med Viral. 2020;92;538-9.

[Crossref]

07. Korber B, Fischer WM, Gnanakaran S, et al. Sheffield COVID-19 Genomics Group Tracking changes in SARS-CoV-2 spike- evidence that D614G increases infectivity of the covid-19 virus. Cell. 2020;182;812-827;e19.

doi: $10.1016 /$ j.cell.2020.06.043 [Crossref]

08. Monteil $\mathrm{V}$, Kwon $\mathrm{H}$, Prado $\mathrm{P}$, et al. Inhibition of SARS-CoV-2 infections in engineered human tissues using clinical-grade soluble human ACE2. Cell. 2020;181;905-913;e7.

doi: $10.1016 /$ j.cell.2020.04.004 [Crossref]

09. Allegra A, Di Gioacchino M, Tonacci A, Musolino C, Gangemi S. Immunopathology of SARS-CoV2 infection- immune cells and mediators, prognostic factors, and immune-therapeutic implications. Int J Mol Sci. 2020;21;E4782.

[Crossref]

10. Lega S, Naviglio S, Volpi S, Tommasini A. Recent insight into SARS-CoV2 immunopathology and rationale for potential treatment and preventive strategies in COVID-19. Vaccines (Basel). 2020; 8;E224.

[Crossref]

11. Stebbing J, Phelan A, Griffin I, et al. COVID-19combining antiviral and anti-inflammatory treatments. Lancet Infect Dis. $2020 ; 20(4) 400-$

2. [Crossref]

12. Fillebeen C, Wilkinson N, Charlebois $E$, et al. Hepcidin-mediated hypoferremic response to acute inflammation requires a threshold of Bmp6/Hjv/Smad signaling. Blood. 2018;132(17)1829-41.

[Crossref]

13. Shoenfeld Y. Corona (COVID-19) time musingsour involvement in COVID-19 pathogenesis, diagnosis, treatment and vaccine planning. Autoimmun Rev. 2020;102538. [Crossref]
14. Rosário C, Zandman-Goddard G, Meyron-Holtz EG, D'Cruz DP, Shoenfeld Y. The hyperferritinemic syndrome- macrophage activation syndrome, Still's disease, septic shock and catastrophic antiphospholipid syndrome. BMC Med. 2013;11;185.

[Crossref]

15. Kuhn LC. Iron regulatory proteins and their role in controlling iron metabolism. Metallomics. $2015 ; 7 ; 232-243$.

[Crossref]

16. Kernan KF, Carcillo JA. Hyperferritinemia and inflammation. International immunology. 2017;29(9)401-409.

[Crossref]

17. Kell DB, Pretorius E. Serum ferritin is an important inflammatory disease marker, as it is mainly a leakage product from damaged cells. Metallomics- integrated biometal science. 2014;6(4)748-773.

[Crossref]

18. Han $\mathrm{Y}$, Zhang $\mathrm{H}, \mathrm{Mu} \mathrm{S}$, et al. Lactate dehydrogenase, a risk factor of severe COVID19 patients. med Rxiv. 2020;03;24;20040162. doi:10.1101/2020.03.24.20040162. Available at: [Article] [Crossref]

19. Kuang Z-S, Yang Y-I, Wei W, et al. Clinical characteristics and prognosis of communityacquired pneumonia in autoimmune diseaseinduced immunocompromised host- a retrospective observational study. World J Emerg Med. 2020;11;145-51. [Crossref]

20. Ding J, Karp JE, Emadi A. Elevated lactate dehydrogenase (LDH) can be a marker of immune suppression in cancer- Interplay between hematologic and solid neoplastic clones and their microenvironments. Cancer Biomark. 2017; 19;353-63.

[Crossref]

21. Mangalmurti N, Hunter CA. Cytokine Stormsunderstanding COVID-19. Immunity. 2020;53;1925. doi: 10.1016/j.immuni.2020.06. 017. [Crossref]

22. Wu C, Chen X, Cai $Y$, et al. Risk factors associated with acute respiratory distress syndrome and death in patients with coronavirus disease 2019 pneumonia in Wuhan, China. JAMA Intern Med. 2020;180;934-43. doi: 10.1001/jamainternmed.2020.0994 [Crossref] 
23. Huang $C$. et al. Clinical features of patients infected with 2019 novel coronavirus in Wuhan, China. The lancet.

2020;395(10223)497-506 [Crossref]

24. Puja Mehta, Daniel F McAuley, Michael Brown, Emilie Sanchez, Rachel S Tattersall, Jessica J Manson, et al. Consider cytokine storm syndromes and immunosuppression. Lancet. 395(10229)1033-1034.

doi:10.1016/S0140-6736(20)30628-0 [Crossref]

25. Becker RC. COVID-19 update- Covid-19associated coagulopathy. J Thromb Thrombolysis. 2020;50;54-67.

[Crossref]

26. Smith SA, Mutch NJ, Baskar D, Rohloff $P$, Docampo R, Morrissey JH. Polyphosphate modulates blood coagulation and fibrinolysis. Proc Natl Acad Sci USA. 2006;103(4)903-908. [Crossref]

27. Subramaniam S, Jurk K, Hobohm L, et al. Distinct contributions of complement factors to platelet activation and fibrin formation in venous thrombus development. Blood. 2017;129(16)2291-2302.

[Crossref]

28. Iba T, Levy JH. Inflammation and thrombosisroles of neutrophils, platelets and endothelial cells and their interactions in thrombus formation during sepsis. J Thromb Haemost. 2018; 16(2)231-241.

[Crossref]
29. Noubouossie DF, Reeves BN, Strahl BD, Key NS. Neutrophils- back in the thrombosis spotlight. Blood. 2019;133(20)2186-2197.

[Crossref]

30. Iba T, Levy JH, Wada H, Thachil J, Warkentin TE, Levi M. Subcommittee on Disseminated Intravascular Coagulation, Differential diagnoses for sepsis-induced disseminated intravascular coagulation- communication from the SSC of the ISTH. J Thromb Haemost. 2019;17(2)415419.

[Crossref]

31. Levi M, Scully M. How I treat disseminated intravascular coagulation. Blood. 2018;131(8)845-854.

[Crossref]

32. Lippi G, Bonfanti L, Saccenti C, Cervellin G. Causes of elevated $\mathrm{D}$-dimer in patients admitted to a large urban emergency department. Eur J Intern Med. 2014;25(1)45-48.

[Crossref]

33. Connors JM, Levy JH. COVID-19 and its implications for thrombosis and anticoagulation. Blood. 2020;135;2033-2040.

[Crossref] 